\title{
Prevalence of myopia and associated risk factors among primary students in Chongqing: multilevel modeling
}

\author{
Zhihao Xie ${ }^{1 \dagger}$, Yue Long ${ }^{2 \dagger}$, Jingxuan Wang ${ }^{1}$, Qiaoqiao Li ${ }^{3}$ and Qiang Zhang ${ }^{1 *}$
}

\begin{abstract}
Background: The prevalence of myopia and associated risk factors among children in Chongqing has not yet been determined. This study investigated the prevalence of myopia and possible relationships between myopia and several related factors among school children in Chongqing.

Methods: This cross-sectional study assessed a sample of 997 children (7-13 years of age) attending primary school in Chongqing. Data were obtained from visual acuity and refractive error measurements and a structured questionnaire. Myopia was defined as visual acuity $<5.0$ and refractive error (spherical equivalent) of $<-0.50$ diopters (D) in either eye. Multilevel modeling was applied to investigate potential risk factors.

Results: The overall prevalence of myopia was 33.9\% [95\% confidence interval $(\mathrm{Cl})=31.0-36.8]$; myopia prevalence significantly increased with age. Girls were at a higher risk of myopia than boys [odds ratio $(\mathrm{OR})=1.449,95 \% \mathrm{Cl}=$ 1.060-1.979]. Children with paternal myopia $(\mathrm{OR}=2.130,95 \% \mathrm{Cl}=1.376-3.297)$ or maternal myopia $(\mathrm{OR}=1.861,95 \%$ $\mathrm{Cl}=1.153-3.002)$ had a higher risk of myopia than those without myopic parents. Children who spent more than 1 $\mathrm{h}$ daily outdoors were less likely to have myopia; meanwhile, children who did homework more than $3 \mathrm{~h}$ daily $(\mathrm{OR}=2.237,95 \% \mathrm{Cl}=1.041-4.804)$, watched television more than $3 \mathrm{~h}$ daily $(\mathrm{OR}=2.106,95 \% \mathrm{Cl}=1.200-3.697)$, or played electronics more than $1 \mathrm{~h}$ daily $(\mathrm{OR}=2.983,95 \% \mathrm{Cl}=2.088-4.262)$ had a higher risk of myopia.
\end{abstract}

Conclusions: Myopia in school children is a serious public health problem in Chongqing. Myopia was significantly positively associated with higher age, female sex, parental myopia, and spending a long time indoors; notably, playing with electronics had the greatest influence on the risk of myopia.

Keywords: Myopia, Prevalence, Risk factors, Playing electronics, Multilevel modeling

\footnotetext{
* Correspondence: qiangzhang@scu.edu.cn

${ }^{\dagger}$ Zhihao Xie and Yue Long contributed equally to this work.

'Department of Epidemiology and Biostatistics, West China School of Public Health and West China Fourth Hospital, Sichuan University, \#16, Section 3, Renmin Nan Lu, Chengdu, Sichuan 610041, People's Republic of China Full list of author information is available at the end of the article
}

(c) The Author(s). 2020 Open Access This article is licensed under a Creative Commons Attribution 4.0 International License, which permits use, sharing, adaptation, distribution and reproduction in any medium or format, as long as you give appropriate credit to the original author(s) and the source, provide a link to the Creative Commons licence, and indicate if changes were made. The images or other third party material in this article are included in the article's Creative Commons licence, unless indicated otherwise in a credit line to the material. If material is not included in the article's Creative Commons licence and your intended use is not permitted by statutory regulation or exceeds the permitted use, you will need to obtain permission directly from the copyright holder. To view a copy of this licence, visit http://creativecommons.org/licenses/by/4.0/. The Creative Commons Public Domain Dedication waiver (http://creativecommons.org/publicdomain/zero/1.0/) applies to the data made available in this article, unless otherwise stated in a credit line to the data. 


\section{Background}

Myopia, which threatens visual quality and eye health, is a common refractive error among children and teenagers worldwide. Notably, the myopia prevalence is particularly high in east Asian countries; the prevalence in children $6-12$ years of age is $53.9 \%$ in Tianjin, China [1], $36.7 \%$ in children aged 5-14 years in Beijing [2], 69.5\% in teenage children in Singapore [3], 24.8\% in 12-yearsolds in Malaysia [4], 22.6\% in Korean children [5]. Studies have suggested that both genetic and environmental factors have a marked impact on myopia in school children. Myopia risk factors thus far include parental myopia [6], near work activities [7, 8], spending a long time studying [2], and prolonged indoor activity [9]; meanwhile, extended outdoor activity has been associated with reduction in the incidence rate of myopia [10].

Notably, ordinary logistic regression was performed in many prior studies $[1,9,11,12]$ to identify myopia risk factors, although the data emanating from student environments are often hierarchically structured; moreover, the ordinary logistic regression model cannot recognize the existence of clustering, resulting in the underestimation of standard errors of regression coefficients [13]. A preferable statistical approach, multilevel modeling, is more suitable for analyzing these data, as it can identify the existence of clustering within hierarchically structured data, thereby improving estimation of effects and corresponding standard errors [14].

While the myopia prevalence among children in large cities in China, including Tianjin, Beijing, and Guangzhou [1, $10,15]$, has previously been reported, the prevalence of myopia and its associated risk factors among children in Chongqing has not yet been determined though the city has the largest population in China, with nearly $40 \%$ of its population living in rural areas. Moreover, multilevel modeling was only used in the study conducted in Guangzhou [15]. Therefore, in the present study, we conducted a crosssectional survey to determine the prevalence of myopia among primary students in Chongqing and investigated potential myopia risk factors by multilevel modeling.

\section{Methods}

\section{Study design and population}

In 2018, we conducted a cross-sectional survey of the prevalence of myopia and its associated risk factors in children attending primary schools from grades 1 to 6 in Dianjiang county, Chongqing city, China. Two-stage stratified cluster sampling was used to select students for study inclusion. In the first stage, 4 primary schools were randomly selected, including 2 rural schools and 2 urban schools. In the second stage, 1 class was randomly selected from each grade of the selected schools. We informed the school principals and class teachers of the related content and procedures of the study. All children in the selected classes were invited to participate in the study, except those with eye diseases. Written informed consent forms were obtained from the children's parents before the eye examinations and questionnaires were administered. The study protocol was approved by the $\mathrm{Si}$ chuan University, West China School of Public Health Institutional Review Board.

\section{Eye examination and questionnaire}

Visual acuity (VA) was assessed without refractive correction in all children using a logarithmic VA chart with a 5point recording at $5 \mathrm{~m}$. Refractometry was performed in all children in a noncycloplegic state by autorefractometry (auto-refractor KR-1, Topcon, Tokyo, Japan). The spherical equivalent refraction (SE) was calculated as the spherical refractive error $+1 / 2$ of the cylindrical refractive error.

The questionnaire items addressed potential risk factors such as demographic characteristics (age, sex, class, and grade level), a genetic factor (parental myopia status), and multiple environmental factors such as the number of times the children performed eye exercises daily, class recess location, daily sleep duration, and time spent outdoors daily. Also, the number of hours spent performing indoor activities such as, doing homework, using computer, watching television and playing with electronics was assessed as well as whether weekly cramming study sessions were attended. Near work activities such as reading while in a dark environment, reading while lying down, and average reading distance.

\section{Definition of myopia}

In our study, myopia was defined as VA $(\log$ MAR $)<5.0$ and refractive error (spherical equivalent) of $<-0.50$ diopters (D) in either eye [16]; these thresholds were applied to reduce the number of false-positive myopia results. Myopia was further divided into three refractive error groups: low myopia $(<-0.5 \mathrm{D}$ to $\geq-3.0 \mathrm{D})$, moderate myopia $(<-3.0 \mathrm{D}$ to $\geq-6.0)$, and high myopia $(<-6.0 \mathrm{D})[15]$.

\section{Statistical analysis}

Statistical analysis was performed using R software (version 3.5.2; R Foundation for Statistical Computing, Vienna, Austria) and MLwiN software (version 3.03; Centre for Multilevel Modeling, University of Bristol, Bristol, UK). The chi-squared test was used to assess differences in myopia prevalence based on demographic parameters. The Cochran-Armitage test for trends was used to examine the association between myopia prevalence and grade level or age. The normality of the continuous variable distributions was assessed by the Shapiro-Wilk test. Data for continuous variables with normal distributions were presented as the mean \pm standard deviation; data for non-normal variables were presented as the median \pm interquartile range. Categorical variables were presented as frequencies of the total. 
A complex, multi-stage sampling design was used and the students were grouped by classes; therefore, the variables may not be independent. Hence, a two-level multiple logistic regression was performed using the MLwiN software to identify risk factors associated with myopia. First, a univariate analysis was performed to evaluate potential associations. Then, multivariate logistic regression modeling was performed to analyze all statistically significant factors found in the univariate analysis. The odds ratio (OR) and corresponding 95\% confidence interval (CI) were calculated to identify myopia risk factors. In the model, $\mathrm{OR}>1.0$ and $P<0.05$ indicated that a parameter was a risk factor, while $\mathrm{OR}<1.0$ and $P<0.05$ indicated that a parameter was a protective factor. All statistical tests were two-sided, and a value of $P<0.05$ was considered statistically significant.

\section{Results}

\section{Study population}

As shown in Table 1, of the 997 children who completed the eye examinations and questionnaires, $52 \%$ were boys and $42.9 \%$ studied in rural schools. The mean (standard deviation) VA of the right eye was $4.83 \pm 0.31$, and that of the left eye was $4.84 \pm 0.30$.

\section{Refractive error}

Refractive error varied with grade level and sex in right eyes: mean SE was $0.15 \mathrm{D}$ in grade 1 boys and $0.08 \mathrm{D}$ in girls. Mean SEs were - 0.04 D, $-0.21 \mathrm{D},-0.61 \mathrm{D},-1.15 \mathrm{D}$, and $-1.05 \mathrm{D}$ for boys from grades 2 to 6 , respectively, while they were $0.08 \mathrm{D},-0.31 \mathrm{D},-0.89 \mathrm{D},-1.47 \mathrm{D}$, and $-1.55 \mathrm{D}$ for girls in the same grades, respectively. In the left eyes,

Table 1 Demographic factors associated with myopia in children

\begin{tabular}{lllll}
\hline Variables & Total, $\mathrm{n}(\%)$ & No myopia, $\mathrm{n}(\%)$ & Myopia, n (\%) & $P$ value \\
\hline $\begin{array}{l}\text { Total } \\
\text { School region }\end{array}$ & $997(100)$ & $659(66.1)$ & $338(33.9)$ & \\
$\quad$ Rural & $428(42.9)$ & $299(69.9)$ & $129(30.1)$ & 0.030 \\
Urban & $569(57.1)$ & $360(63.3)$ & $209(36.7)$ & \\
Gender & & & & \\
Male & $523(52.5)$ & $366(70.0)$ & $157(30.0)$ & 0.007 \\
Female & $474(47.5)$ & $293(61.8)$ & $181(38.2)$ & \\
Age (years) & & & & \\
7 & $141(14.1)$ & $127(90.1)$ & $14(9.9)$ & $<0.001$ \\
8 & $135(13.5)$ & $122(90.4)$ & $13(9.6)$ & \\
9 & $153(15.3)$ & $115(75.2)$ & $38(24.8)$ & \\
10 & $179(18.0)$ & $102(57.0)$ & $72(40.2)$ & \\
11 & $195(19.6)$ & $92(47.2)$ & $103(52.8)$ & \\
12 & $172(17.3)$ & $88(51.2)$ & $84(48.8)$ & \\
13 & $22(2.2)$ & $8(36.4)$ & $14(63.6)$ & \\
\hline
\end{tabular}

mean SEs were 0.27 D, 0.08 D, - 0.09 D, - 0.52 D, - 0.93 D, and $-0.93 \mathrm{D}$ for boys from grades 1 to 6 , respectively, while they were $0.19 \mathrm{D}, 0.15 \mathrm{D},-0.25 \mathrm{D},-0.69 \mathrm{D},-1.34 \mathrm{D}$, and $-1.38 \mathrm{D}$ for girls in the same grades, respectively.

Refractive error varied with age and sex in right eyes: mean SEs were 0.14 D, 0.04 D, $-0.26 \mathrm{D},-0.51 \mathrm{D},-1.22$ $\mathrm{D},-0.97 \mathrm{D}$, and $-1.15 \mathrm{D}$ for boys aged 7 to 13 years, respectively, while they were $0.17 \mathrm{D}, 0.01 \mathrm{D},-0.28 \mathrm{D},-0.97$ $\mathrm{D},-1.54 \mathrm{D},-1.43 \mathrm{D}$, and $-1.48 \mathrm{D}$ for girls of the same ages, respectively. In the left eyes, mean SEs were $0.28 \mathrm{D}$, $0.11 \mathrm{D},-0.09 \mathrm{D},-0.44 \mathrm{D},-0.99 \mathrm{D},-0.94 \mathrm{D}$, and -0.50 $\mathrm{D}$ for boys aged 7 to 13 years, respectively, while they were $0.27 \mathrm{D},-0.03 \mathrm{D},-0.10 \mathrm{D},-0.81 \mathrm{D},-1.34 \mathrm{D},-1.29 \mathrm{D}$, and $-1.23 \mathrm{D}$ for girls of the same ages, respectively.

\section{Prevalence of myopia}

The overall prevalence of myopia was $33.9 \%$ in our study. When stratified according to myopia categories, low myopia had the highest prevalence, followed by moderate and high myopia (Table 2). Moreover, myopia prevalence significantly increased with increasing grade level $\left(x^{2}\right.$ trend test $=127.63, P<0.001$ ), ranging from $11.0 \%$ in grade 1 to $51.9 \%$ in grade 6 . Likewise, the prevalence of myopia significantly increased with age $\left(\chi^{2}\right.$ trend test $=124.62, P<0.001$ ), ranging from $9.9 \%$ at age 7 to $63.6 \%$ at age 13 . Moreover, the prevalence in girls was significantly higher than that in boys $(38.2 \%$ vs. $\left.30.0 \%, X^{2}=7.40, P=0.007\right)$. Compared with children studying in rural schools, the prevalence of myopia was higher among children studying in urban schools $\left(x^{2}=4.74, P=0.03\right)$.

Table 2 Prevalence rate and categories of myopia

\begin{tabular}{lllll}
\hline Variables & $\begin{array}{l}\text { Myopia } \\
(\% ; 95 \% \mathrm{Cl})\end{array}$ & \multicolumn{3}{l}{ Myopia categories n (\%) } \\
\cline { 4 - 5 } & & Low & Moderate & High \\
\hline Total & $33.9 ; 31.0-36.8$ & $258(76.3)$ & $73(21.6)$ & $7(2.1)$ \\
School region & & & & \\
Rural & $30.1 ; 27.2-33.1$ & $104(80.6)$ & $23(17.8)$ & $2(1.6)$ \\
Urban & $36.7 ; 33.8-39.7$ & $154(73.7)$ & $50(23.9)$ & $5(2.4)$ \\
Gender & & & & \\
Male & $30.0 ; 27.1-33.0$ & $120(76.4)$ & $35(22.3)$ & $2(1.3)$ \\
Female & $38.2 ; 35.2-41.1$ & $138(76.2)$ & $38(21.0)$ & $5(2.8)$ \\
Age (years) & & & & \\
7 & $9.9 ; 5.0-14.9$ & $14(100)$ & $0(0)$ & $0(0)$ \\
8 & $9.6 ; 4.7-14.6$ & $12(92.3)$ & $1(7.7)$ & $0(0)$ \\
9 & $24.8 ; 18.0-31.7$ & $30(78.9)$ & $6(15.8)$ & $2(5.3)$ \\
10 & $40.2 ; 33.0-47.4$ & $58(80.6)$ & $13(18.1)$ & $1(1.3)$ \\
11 & $52.8 ; 45.8-59.8$ & $70(68.0)$ & $31(30.1)$ & $2(1.9)$ \\
12 & $48.8 ; 41.4-56.3$ & $62(73.8)$ & $20(23.8)$ & $2(2.4)$ \\
13 & $63.6 ; 43.5-83.7$ & $12(85.7)$ & $2(14.3)$ & $0(0)$ \\
\hline
\end{tabular}

Cl confidence interval 
Risk factors identified by multilevel logistic model

The data had a two-level hierarchical structure with 997 children nested within 24 classes. The level 1 units were individual children and the level 2 units were classes. First, a two-level null model without explanatory variables was fitted. The predictive or penalized quasi-likelihood was implemented in MLwiN to generate discrete response multilevel models. The linearization method, based on a Taylor series expansion, was performed to transform a discrete response model to a continuous response model; the model was then estimated using iterative generalized least squares [17].

Null model:

$$
\begin{aligned}
& \log \left(\pi_{i j}\right)=\beta_{0 j} \\
& \beta_{0 j}=-0.913(0.217)+u_{0 j} \\
& u_{0 j} \sim N\left(0, \Omega_{u}\right): \Omega_{u}=[0.960(0.322)]
\end{aligned}
$$

In the null model, the intercept for class $j$ was -0.913 (standard error $=0.217)+u_{0 j}$, where the variance of $u_{0 j}$ was estimated as 0.960 (standard error $=0.322$ ). The Wald chi-squared test statistic was 8.86 with a $P$-value of 0.003 . Therefore, we concluded that there were significant differences between classes. We fitted a two-level random intercept model to analyze potential factors associated with myopia because the data appeared clustered at the class level.

In the univariate analysis, the prevalence of myopia was significantly associated with increasing age $(P<$ $0.001)$, female sex $(P=0.014)$, performing more eye exercises $(P=0.047)$, paternal myopia $(P<0.001)$, maternal myopia $(P=0.019)$, and reading while lying down $(P=0.007)$ as well as spending less time outdoors $(P<0.001)$, more time on homework $(P=$ $0.021)$, more time watching television $(P=0.001)$, and more time playing with electronics $(P<0.001)$. The prevalence of myopia was not significantly associated with region, class recess location, sleeping duration, cramming for study sessions, computer usage, reading while in a dark environment, or reading distance (Fig. 1).

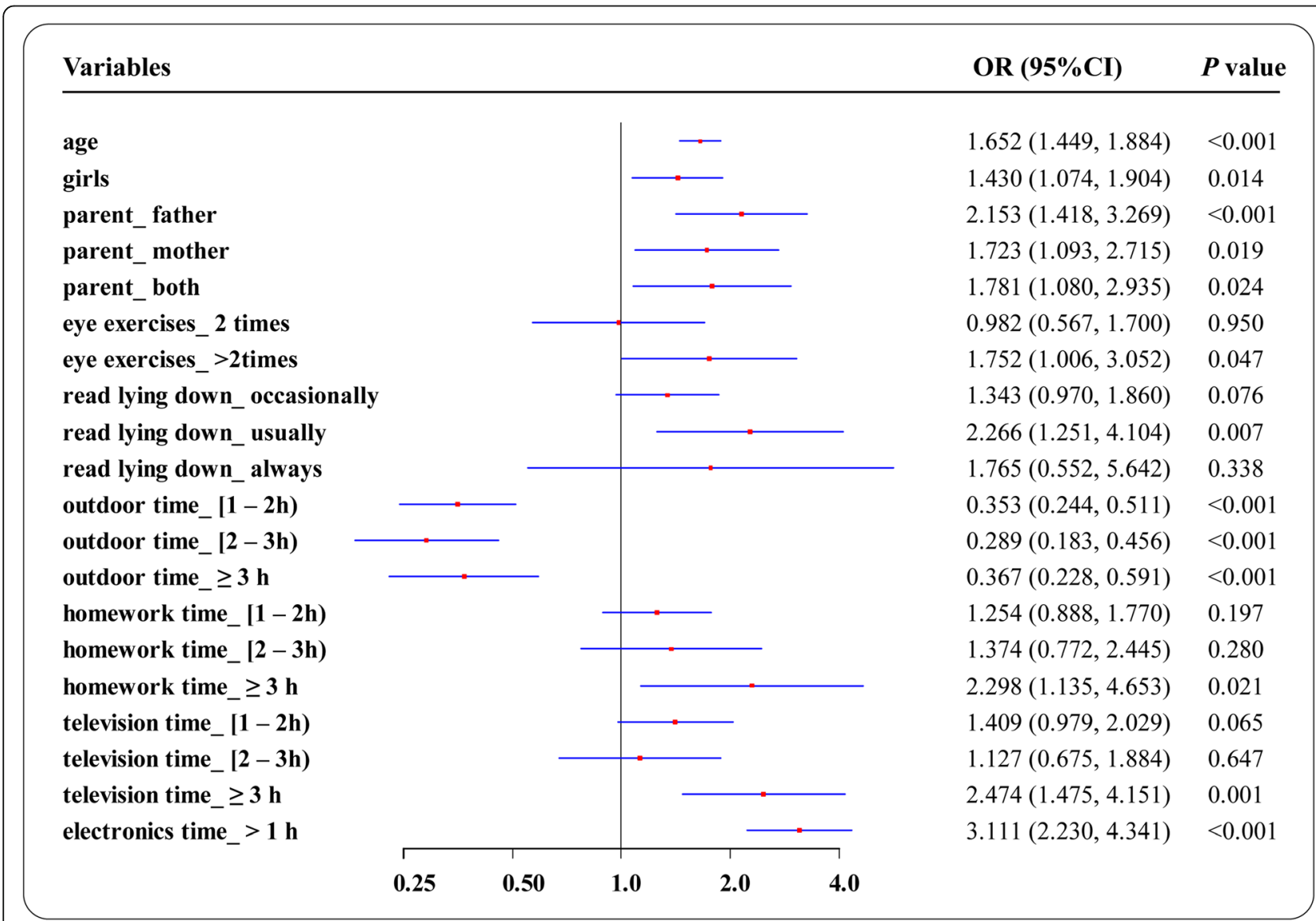

Fig. 1 Associations between potential factors and myopia in univariate analysis. Myopia was significantly associated with age, sex, parental myopia, performing eye exercises, reading while lying down, less time outdoors, more time for homework, more time watching television, and more time playing with electronics; playing with electronics had the highest odds ratio of 3.111 (95\% confidence interval: $2.230-4.341$ ) 
Full model:

$$
\begin{aligned}
& \log \left(\pi_{i j}\right)=\beta_{0 j}+0.473(0.075) \text { age } \_1_{i j}+0.371(0.159) \text { gender_ } 1_{i j} \\
& +0.756(0.223) \text { parent_ } 1_{i j}+0.621(0.244) \text { parent_ } 2_{i j} \\
& +0.447(0.278) \text { parent_ } 3{ }_{i j}-0.980(0.195) \text { outdoor } \_1_{i j} \\
& -1.335(0.245) \text { outdoor_ } 2 i_{i j}-1.101(0.258) \text { outdoor_ } 3 i j \\
& +0.325(0.182) \text { homework } \_1 \text { ij }+0.370(0.320) \text { homework } \_2_{i j} \\
& +0.805(0.390) \text { homework } \_3_{i j}+0.386(0.198) \text { television } \_1_{i j} \\
& +0.027(0.294) \text { television_ } 22_{i j}+0.745(0.287) \text { television_ } 3 i j \\
& +1.093(0.182) \text { electronics } \_1_{i j} \\
& \beta_{0 j}=-5.769(0.760)+u_{0 j} \\
& u_{0 j} \sim N\left(0, \Omega_{u}\right): \Omega_{u}=[0.192(0.101)] \\
& \operatorname{Var}\left(\operatorname{myopia}_{i j} \mid \pi_{i j}\right)=\pi_{i j}\left(1-\pi_{i j}\right) / n_{i j}
\end{aligned}
$$

The definitions of the variables in the two-level random intercept model were shown in supplementary Table 1. In the multivariate analysis based on the full model, the presence of myopia was taken as the dependent parameter and all statistically significant factors in the univariate analysis were taken as independent variables. The analysis revealed that myopia was associated with age; female sex; paternal and maternal myopia; less time spent outdoors; more time spent on homework, watching television, and playing with electronics. The joint chi-squared test statistic for the full model was 169.673 $(P<0.001)$. The between-class variance decreased from 0.960 to 0.192 ; thus, some of the variation in myopia between classes was explained by the differences in age, sex, parental myopia, and time spent outdoors.

The results of multivariate analysis demonstrated that as children became older, their risk of myopia increased $(\mathrm{OR}=1.605,95 \% \mathrm{CI}=1.385-1.859)$ (Fig. 2). The results also showed that the prevalence of myopia was higher in girls than in boys $(P=0.019)$; girls had a 1.449 -fold $(95 \%$ $\mathrm{CI}=1.060-1.979)$ higher risk of myopia than boys. Furthermore, the children with paternal myopia $(\mathrm{OR}=$ $2.130,95 \% \mathrm{CI}=1.376-3.297)$ or maternal myopia $(\mathrm{OR}=$ $1.861,95 \% \mathrm{CI}=1.153-3.002$ ) had a higher risk of myopia than those without myopic parents. In analysis of outdoor and indoor activities, children who spent more than $1 \mathrm{~h}$ daily outdoors had a lower risk of myopia ( $>1$ $\mathrm{h}, \mathrm{OR}=0.375,95 \% \mathrm{CI}=0.256-0.550 ;>2 \mathrm{~h}, \mathrm{OR}=0.263$, $95 \% \mathrm{CI}=0.163-0.425 ;>3 \mathrm{~h}, \quad \mathrm{OR}=0.333, \quad 95 \% \mathrm{CI}=$ $0.201-0.551$ ). Children who spent more than $3 \mathrm{~h}$ daily

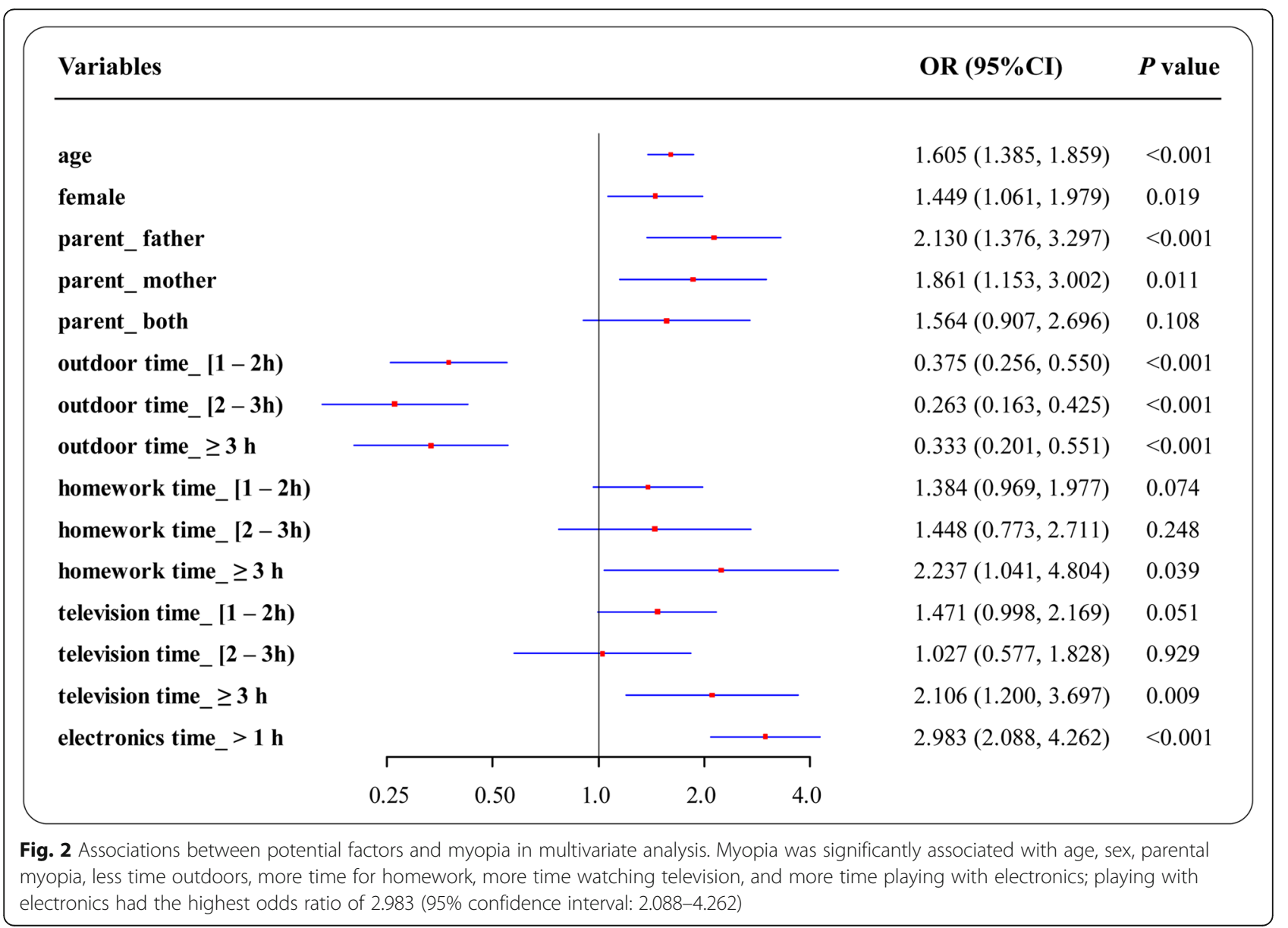


on homework, watched television more than $3 \mathrm{~h}$ daily or played with electronics more than $1 \mathrm{~h}$ daily all had a higher risk of myopia; the respective ORs were 2.237 (95\% CI $=1.041-4.804), 2.106 \quad(95 \% \mathrm{CI}=1.200-3.697)$, and $2.983(95 \% \mathrm{CI}=2.088-4.262)$. The variance inflation factor (VIF) is used to quantify multicollinearity severity in statistical analyses. It provides an index that measures the extent of increase in the variance of an estimated regression coefficient because of collinearity. VIF values ranging from 0 to 10 are considered not to indicate multicollinearity. In the multivariate model, the VIFs of age, sex, parental myopia status, outdoor time, homework time, television time, and electronics time were 1.034, $1.033,1.046,1.108,1.066,1.160,1.051$, respectively. Hence, there was no multicollinearity in our multivariate analysis.

\section{Discussion}

To the best of our knowledge, the present study is the first investigation of the prevalence of myopia and its associated risk factors among primary school children in Chongqing. The overall prevalence of myopia among primary school children in Chongqing was $33.9 \%$, which was higher than the prevalence reported in several other countries: $3.3 \%$ in children aged $6-7$ years and $19.9 \%$ in children aged 12-13 years in Ireland [18], as well as in Malaysia [4] and Korea [5]. Furthermore, the prevalence of myopia in Chongqing was higher than that in some areas of China, as reports indicated a prevalence of $2.4 \%$ in grade 1 students in Mojiang [19], 23.1\% in children aged 6-18 years in Handan [20], and $26.4 \%$ in adults in Yunnan [21]; these data suggest that myopia is a serious public health problem in Chongqing along with other areas of China.

In most prior studies $[1,9,11]$, ordinary logistic regression was performed to identify myopia risk factors; however, the intra-cluster dependency of hierarchically structured data can violate the assumption of independence in ordinary logistic regression, resulting in biased estimates. Hence, a multilevel model was used in the present study to assess hierarchically structured data. Multilevel modeling provides better statistical models that match real-world data, because it can address parameters that vary at more than one level, examine cross-level effects, and simultaneously decompose the variances of the variables into within-group and between-group components [13, 22]. The two-level logistic model used in this study separated the effects of individual myopia from those of the average myopia in a class. Although performing eye exercises and reading while lying down were significantly associated with myopia in univariate analysis; they were not significantly associated with myopia in the multivariate analysis. Our cross-sectional study using multilevel modeling revealed that myopia was associated with increased age, female sex, parental myopia, shorter time outdoors, and longer time indoors.

The higher prevalence of myopia among children in urban schools, compared with those in rural schools, was identified by the chi-squared test; this was not found in multilevel model, because the influence of school region, accepted as an independent variable in the twolevel model, had already been addressed in the two-level model. Similar to a previous study [23], the higher prevalence of myopia among children in urban schools might result from more time spend on indoor activities than outdoor activities. We also found that the prevalence of myopia in girls was higher than that in boys, which was consistent with the findings in other Chinese locations, such as Guangzhou [15] and Xichang [24]. Previous studies indicated that older children had a higher risk of myopia [2, 15, 25], which was further confirmed by our study.

As in other countries [6, 26] and other large cities in China $[15,27]$, we found that parental myopia, typically regarded as a hereditary risk factor for myopia in different age and ethnic groups, was a significant risk factor associated with myopia in Chongqing. In a prospective cohort study, Saw et al. confirmed that parental myopia remained a significant risk factor for myopia, regardless of the definitions of incident myopia [26]. In addition, Guo et al. reported a significant positive relationship between the incidence of myopia and parental myopia in a longitudinal cohort of children in Beijing [10]. However, we did not find a dose-dependent pattern between myopia prevalence in children and the myopic status of their parents [12]; this may have been because the participants in their study were different from those in our study, and because the dose-dependent association may only play a role in older children who have already been exposed to environmental risk factors.

In addition to this genetic factor, environmental factors contribute significantly to the prevalence of myopia [28]. As in previous cross-sectional studies [3, 24, 27, 29], our study also demonstrated that more time involved in outdoor activities had protective effects on eye health. The prevalence of myopia in children of Chinese ethnicity was significantly higher than that in children in Singapore (29.1\%) and in Sydney (3.3\%); notably, children in Sydney spent substantially more time for outdoor activities [29]. Also, prospective cohort studies demonstrated that shorter time outdoors was a statistical risk factor for myopia. Guggenheim et al. reported that both time spent outdoors and physical activity were associated with incident myopia, and that time spent outdoors had a greater effect [30]. Guo et al. [10] found that, in univariate analysis, the incidence of myopia was significantly associated with a short time outdoors, and 
long times indoors focused on studying; however, multivariate analysis revealed that, only a short time outdoors was significantly associated with a higher incidence of myopia. In addition to the evidence provided by these cross-sectional and prospective cohort studies, a randomized clinical trial in China showed that outdoor activity can reduce the incidence rate of myopia [31]. Furthermore, the association between outdoor activity and myopia has been demonstrated in different age and ethnic groups [11, 32, 33].

Increased time spent on indoor activities, including homework, watching television, and playing with electronic devices, increased the risk of myopia in the present study; this finding was similar to that in a study conducted in Beijing [27]. In addition, Harrington et al. [9] found that there was a dose-dependent relationship between myopic prevalence of schoolchildren and the leisure time they spent in reading/writing. Contrary to the reports of previous studies that near work was a significant risk factor for myopia [7, 8, 34], the average reading distance was not associated with myopia in the present study; however, a related practice, reading while lying down was associated with myopia in our univariate analysis. Notably, this was not a risk factor in our multivariate analysis. Interestingly, the results of the two-level model showed that playing with electronics more than $1 \mathrm{~h}$ daily was a significant risk factor for myopia with the highest $\mathrm{OR}$ value $(\mathrm{OR}=3.111,95 \% \mathrm{CI}=$ 2.230-4.341), indicating that this activity had the greatest effect on the risk of myopia; this finding was not reported in other studies conducted in China [2, 15]. Considering the above risk factors for myopia, public intervention measures related to increasing the time outdoors should be implemented to reduce the incidence of myopia.

A potential limitation in this study should be mentioned. When the prevalence rate is less than $10 \%$, the OR value is similar to the prevalence rate ratio (PRR) value. However, the prevalence rate of myopia was $33.9 \%$ in our study, so the OR is different from the PRR and substantially overestimates the relative risk of myopia.

\section{Conclusions}

In summary, the overall prevalence of myopia was relatively high in the present study, suggesting that myopia is a serious public health problem among school children in Chongqing. Myopia was significantly positively associated with female sex, increased age, parental myopia, shorter time outdoors, and longer time indoors. Importantly, playing with electronics more than $1 \mathrm{~h}$ daily had the greatest effect on risk of myopia.

\section{Supplementary information}

Supplementary information accompanies this paper at https://doi.org/10. 1186/s12886-020-01410-3.

Additional file 1: Table S1. Definitions of variables in two-level random intercept model.

\section{Abbreviations}

Cl: Confidence interval; D: Diopters; OR: Odds ratio; SE: Spherical equivalent refraction; VA: Visual acuity

\section{Acknowledgements}

The authors thank all children and their families for participating in this study.

\section{Authors' contributions}

ZX, YL and QZ conceived and planned this study and take full responsibility for the paper. ZX, YL, JW, QL and QZ contributed to the analysis and interpretation of the clinical and genetic data. ZX took the lead in writing the manuscript. QZ supervised this study and contributed to revision of the paper. All authors read and approved the final manuscript.

\section{Funding}

Not applicable.

\section{Availability of data and materials}

The datasets used and/or analyzed during this study are available from the corresponding author upon reasonable request.

\section{Ethics approval and consent to participate}

The study was approved by the Sichuan University, West China School of Public Health Institutional Review Board, and was conducted in accordance with the ethical standards of the Declaration of Helsinki. Written informed consent forms were obtained from the children's parents before the eye examinations and questionnaires.

\section{Consent for publication}

Not applicable.

\section{Competing interests}

The authors declare that they have no competing interests.

\section{Author details}

${ }^{1}$ Department of Epidemiology and Biostatistics, West China School of Public Health and West China Fourth Hospital, Sichuan University, \#16, Section 3, Renmin Nan Lu, Chengdu, Sichuan 610041, People's Republic of China.

${ }^{2}$ Department of Ophthalmology, West China Hospital, Sichuan University,

Chengdu, China. ${ }^{3}$ School of Education, Soochow University, Suzhou, China.

Received: 25 April 2019 Accepted: 30 March 2020

Published online: 15 April 2020

\section{References}

1. Liu S, Ye S, Wang Q, Cao Y, Zhang X. Breastfeeding and myopia: a crosssectional study of children aged 6-12 years in Tianjin, China. Sci Rep. 2018; 8(1):10025.

2. Lyu $Y$, Zhang $H$, Gong $Y$, Wang $D$, Chen $T$, Guo $X$, et al. Prevalence of and factors associated with myopia in primary school students in the Chaoyang District of Beijing, China. Jpn J Ophthalmol. 2015;59(6):421-9.

3. Dirani M, Tong L, Gazzard G, Zhang X, Chia A, Young TL, et al. Outdoor activity and myopia in Singapore teenage children. Br J Ophthalmol. 2009; 93(8):997-1000

4. Goh PP, Abqariyah Y, Pokharel GP, Ellwein LB. Refractive error and visual impairment in school-age children in Gombak District, Malaysia. Ophthalmology. 2005;112(4):678-85.

5. Lim HT, Yoon JS, Hwang SS, Lee SY. Prevalence and associated sociodemographic factors of myopia in Korean children: the 2005 third Korea National Health and nutrition examination survey (KNHANES III). Jpn J Ophthalmol. 2012;56(1):76-81. 
6. Ip JM, Huynh SC, Robaei D, Rose KA, Morgan IG, Smith W, et al. Ethnic differences in the impact of parental myopia: findings from a populationbased study of 12-year-old Australian children. Invest Ophthalmol Vis Sci. 2007:48(6):2520-8.

7. Rahi JS, Cumberland PM, Peckham CS. Myopia over the lifecourse: prevalence and early life influences in the 1958 British birth cohort. Ophthalmology. 2010;118(5):797-804.

8. Han SB, Jang J, Yang HK, Hwang JM, Park SK. Prevalence and risk factors of myopia in adult Korean population: Korea national health and nutrition examination survey 2013-2014 (KNHANES VI). PLoS One. 2019;14(1): e0211204.

9. Harrington SC, Stack J, O'Dwyer V. Risk factors associated with myopia in schoolchildren in Ireland. Br J Ophthalmol. 2019;103:1803-9. https://doi.org/ 10.1136/bjophthalmol-2018-313325

10. Guo $Y$, Liu $L$, Tang $P, L V Y Y$, Feng $Y, X u L$, et al. Outdoor activity and myopia progression in 4-year follow-up of Chinese primary school children: the Beijing children eye study. PLoS One. 2017;12(4):e0175921.

11. Tideman JWL, Polling JR, Jaddoe WW, Vingerling JR, Klaver CCW. Environmental risk factors can reduce axial length elongation and myopia incidence in 6- to 9-year-old children. Ophthalmology. 2019;126(1):127-36.

12. Wang L, Du M, Yi H, Duan S, Guo W, Qin P, et al. Prevalence of and factors associated with myopia in Inner Mongolia medical students in China, a cross-sectional study. BMC Ophthalmol. 2017;17(1):52.

13. Enders CK, Tofighi D. Centering predictor variables in cross-sectional multilevel models: a new look at an old issue. Psychol Methods. 2007:12(2): 121-38.

14. Adewale AJ, Hayduk L, Estabrooks CA, Cummings GG, Midodzi WK, Derksen L. Understanding hierarchical linear models: applications in nursing research. Nurs Res. 2007;56(4 Suppl):S40-6.

15. Guo L, Yang J, Mai J, Du X, Guo Y, Li P, et al. Prevalence and associated factors of myopia among primary and middle school-aged students: a school-based study in Guangzhou. Eye (Lond). 2016;30(6):796-804.

16. Hashemi H, Rezvan F, Ostadimoghaddam H, Abdollahi M, Hashemi M, Khabazkhoob M. High prevalence of refractive errors in a rural population: 'Nooravaran Salamat' Mobile eye clinic experience. Clin Exp Ophthalmol. 2013:41(7):635-43.

17. Goldstein H, Rasbash J. Improved approximations for multilevel models with binary responses. J R Stat Soc Series A Stat Soc. 1996;159(3):505-13.

18. Harrington SC, Stack J, Saunders K, O'Dwyer V. Refractive error and visual impairment in Ireland schoolchildren. Br J Ophthalmol. 2018:103:1112-8. https://doi.org/10.1136/bjophthalmol-2018-312573.

19. Pan CW, Wu RK, Li J, Zhong H. Low prevalence of myopia among school children in rural China. BMC Ophthalmol. 2018;18(1):140.

20. Lin Z, Gao TY, Vasudevan B, Ciuffreda KJ, Liang YB, Jhanji V, et al. Near work, outdoor activity, and myopia in children in rural China: the Handan offspring myopia study. BMC Ophthalmol. 2017;17(1):203.

21. Wang M, Cui J, Shan G, Peng X, Pan L, Yan Z, et al. Prevalence and risk factors of refractive error: a cross-sectional study in Han and Yi adults in Yunnan, China. BMC Ophthalmol. 2019;19(1):33.

22. Galletta M, Portoghese I, Melis P, Gonzalez CIA, Finco G, D'Aloja E, et al. The role of collective affective commitment in the relationship between workfamily conflict and emotional exhaustion among nurses: a multilevel modeling approach. BMC Nurs. 2019;18:5.

23. Mingguang $H$, Wenyong $H$, Yingfeng $Z$, Li H, Ellwein LB. Refractive error and visual impairment in school children in rural southern China. Ophthalmology. 2007;114(2):374-82.

24. Lu B, Congdon N, Liu X, Choi K, Lam DS, Zhang M, et al. Associations between near work, outdoor activity, and myopia among adolescent students in rural China: the Xichang pediatric refractive error study report no. 2. Arch Ophthalmol. 2009;127(6):769-75.

25. Theophanous C, Modjtahedi BS, Batech M, Marlin DS, Luong TQ, Fong DS Myopia prevalence and risk factors in children. Clin Ophthalmol. 2018;12 $1581-7$.

26. Saw SM, Shankar A, Tan SB, Taylor H, Tan DT, Stone RA, et al. A cohort study of incident myopia in Singaporean children. Invest Ophthalmol Vis Sci. 2006 47(5):1839-44

27. Guo $Y$, Liu $L, X u L, L v Y Y$, Tang P, Feng $Y$, et al. Outdoor activity and myopia among primary students in rural and urban regions of Beijing Ophthalmology. 2013;120(2):277-83
28. Low W, Dirani M, Gazzard G, Chan YH, Zhou HJ, Selvaraj P, et al. Family history, near work, outdoor activity, and myopia in Singapore Chinese preschool children. Br J Ophthalmol. 2010;94(8):1012-6.

29. Rose KA, Morgan IG, Ip J, Kifley A, Huynh S, Smith W, et al. Outdoor activity reduces the prevalence of myopia in children. Ophthalmology. 2008;115(8): 1279-85.

30. Guggenheim JA, Northstone K, McMahon G, Ness AR, Deere K, Mattocks C, et al. Time outdoors and physical activity as predictors of incident myopia in childhood: a prospective cohort study. Invest Ophthalmol Vis Sci. 2012; 53(6):2856-65

31. He M, Xiang F, Zeng Y, Mai J, Chen Q, Zhang J, et al. Effect of time spent outdoors at school on the development of myopia among children in China: a randomized clinical trial. JAMA. 2015:314(11):1142-8.

32. Jones LA, Sinnott LT, Mutti DO, Mitchell GL, Moeschberger ML, Zadnik K. Parental history of myopia, sports and outdoor activities, and future myopia. Invest Ophthalmol Vis Sci. 2007;48(8):3524-32.

33. Singh NK, James RM, Yadav A, Kumar R, Asthana S, Labani S. Prevalence of myopia and associated risk factors in schoolchildren in North India. Optom Vis Sci. 2019;96(3):200-5.

34. Ip JM, Saw SM, Rose KA, Morgan IG, Kifley A, Wang JJ, et al. Role of near work in myopia: findings in a sample of Australian school children. Invest Ophthalmol Vis Sci. 2008:49(7):2903-10.

\section{Publisher's Note}

Springer Nature remains neutral with regard to jurisdictional claims in published maps and institutional affiliations.
Ready to submit your research? Choose BMC and benefit from:

- fast, convenient online submission

- thorough peer review by experienced researchers in your field

- rapid publication on acceptance

- support for research data, including large and complex data types

- gold Open Access which fosters wider collaboration and increased citations

- maximum visibility for your research: over $100 \mathrm{M}$ website views per year

At $\mathrm{BMC}$, research is always in progress.

Learn more biomedcentral.com/submissions 